\title{
Identification of novel SIRT2-selective inhibitors using a click chemistry approach
}

\author{
Prima R. Tatum, ${ }^{\mathrm{a}}$ Hideyuki Sawada, ${ }^{\mathrm{b}}$ Yosuke Ota, ${ }^{\mathrm{b}}$ Yukihiro Itoh, ${ }^{\mathrm{b}}$ Peng Zhan, ${ }^{\mathrm{b}}$ Naoya \\ Ieda, ${ }^{a}$ Hidehiko Nakagawa ${ }^{\mathrm{a}}$ and Naoki Miyata ${ }^{\mathrm{a}, *}$ and Takayoshi Suzuki, ${ }^{\mathrm{b}, *}$ \\ ${ }^{\mathrm{a}}$ Graduate School of Pharmaceutical Sciences, Nagoya City University, 3-1 Tanabe-dori, Mizuho-ku, Nagoya, Aichi 467- \\ 8603, Japan \\ ${ }^{\mathrm{b}}$ Graduate School of Medical Science, Kyoto Prefectural University of Medicine, 13 Taishogun Nishitakatsukasa-Cho, Kita- \\ ku, Kyoto 603-8334, Japan
}

Keywords: sirtuin; histone deacetylase; inhibitor; isozyme selectivity.

*Corresponding author. Tel and fax: +81-75-465-7659; e-mail: suzukit@koto.kpu-m.ac.jp; miyata-n@phar.nagoya-cu.ac.jp

\begin{abstract}
A series of 114 SIRT inhibitor candidates was assembled using 'click chemistry', by reacting two alkynes bearing 2anilinobenzamide pharmacophore with 57 azide building blocks in the presence of $\mathrm{Cu}(\mathrm{I})$ catalyst. Screening identified two SIRT2selective inhibitors, which were more SIRT2-selective than AGK2, a known SIRT2 inhibitor. These findings will be useful for further development of SIRT2-selective inhibitors.
\end{abstract}

Sirtuins are a class of enzymes known as $\mathrm{NAD}^{+}$ dependent protein deacetylases that regulate a variety of biological processes including aging, transcription and metabolism. ${ }^{1-3}$ Humans have seven distinct sirtuin gene products (SIRT1-7). ${ }^{4}$ Among the seven human sirtuins, SIRT2 is the only cytosolic protein. SIRT2 deacetylates nonhistone proteins in cytoplasm and is involved in various biological events. For example, SIRT2 destabilizes microtubules by deacetylating $\alpha$-tubulin, ${ }^{5}$ and deacetylation of phosphoenolpyruvate carboxykinase by SIRT2 regulates gluconeogenesis. ${ }^{6}$ Although the functions of SIRT2 have not yet been fully understood, they have been suggested to be associated with certain disease states. It has been reported that inhibition of SIRT2 rescued $\alpha$-synuclein toxicity and modified inclusion morphology in a cellular model of Parkinson's disease. ${ }^{7}$ SIRT2 inhibition also has been reported to reduce neuronal cholesterol reduction and to be neuroprotective in cellular models of Huntington's disease. ${ }^{8}$ Therefore, SIRT2-selective inhibitors are of interest not only as tools for elucidating in detail the biological functions of the enzyme, but can also be considered as potential therapeutic agents for neurodegenerative diseases.
Several classes of small molecule SIRT2-selective inhibitors have been identified so far (Fig. 1). These include AGK2 (1) ${ }^{7}$ compounds $\mathbf{2}^{9} \mathbf{3}^{10}$ and $\mathbf{4}^{11}$ Previously, we identified 2-anilinobenzamide $\mathbf{5}$ as SIRT1-selective inhibitors. ${ }^{12,13}$ The structure-activity relationship (SAR) studies of anilinobenzamide derivatives revealed that meta- or para-substituted 2anilinobenzamides such as compounds $\mathbf{6}$ and $\mathbf{7}$ tend to show SIRT2 selectivity (Fig. 2). ${ }^{{ }_{4}}$
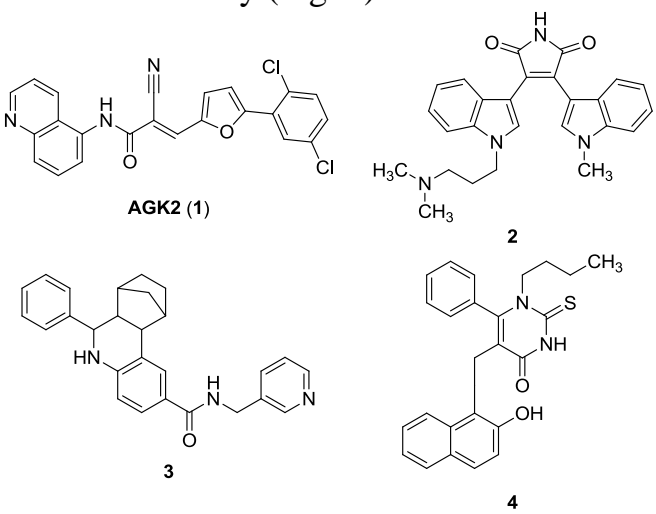

Figure 1. Reported small molecule SIRT2-selective inhibitors. 


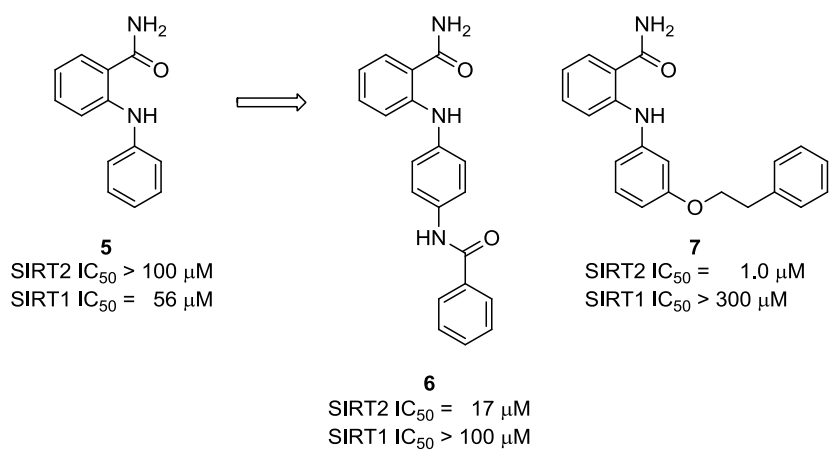

Figure 2. SIRT2-selective inhibitors discovered by our group.

We and other groups previously described the identification of enzyme inhibitors from a triazole compound library generated by the use of $\mathrm{Cu}(\mathrm{I})$ catalyzed azide-alkyne cycloaddition (CuAAC), ${ }^{15-17}$ a representative reaction in click chemistry. ${ }^{18}$ Following these studies, we performed a further click chemistry approach, seeking to find novel SIRT2-selective inhibitors. We describe here the rapid identification of novel SIRT2-selective inhibitors via the use of click chemistry to generate a library of meta- and parasubstituted 2-anilinobenzamides as SIRT inhibitor candidates.

Based on the previous SAR studies of anilinobenzamide derivatives, ${ }^{14}$ we designed a library of candidates as SIRT inhibitors bearing a triazole group at the meta or para position (Fig. 3).

Accordingly, we prepared two alkynes A1 and A2 as shown in Scheme 1. Treatment of iodobenzoic acids $\mathbf{8}$ with thionyl chloride afforded the corresponding acid chlorides which were converted to Weinreb amides 9 by the reaction with $\mathrm{N}, \mathrm{O}$-dimethylhydroxylamine. Buchwald-Hartwig reaction between 2-aminobenzamide and compounds 9 using 2-dicyclohexylphosphino$2^{\prime}, 4^{\prime}, 6^{\prime}$-triisopropylbiphenyl as a ligand gave diphenylamine compounds 10. Compounds 10 were allowed to react with lithium aluminum hydride at $0{ }^{\circ} \mathrm{C}$ to give aldehydes $\mathbf{1 1}$ and subsequent Seyferth-Gilbert homologation using dimethyl 1diazoacetonylphosphonate yielded the desired alkynes A1 and A2.

Next, the 114-member 2-anilinobenzamide library was assembled using click chemistry in microtiter plates. Each of the two alkynes A (1 eq) was mixed with each of the 57 azides B (Fig. 4) (1.2 eq), which were previously prepared by us, ${ }^{16,17,19}$ in the presence of $\mathrm{CuSO}_{4}(0.2 \mathrm{eq})$, sodium ascorbate $(1 \mathrm{eq})$, and tris[(1benzyl-1H-1,2,3-triazol-4-yl)methyl]amine (TBTA) (0.2 eq) in a solvent mixture of DMSO/ $\mathrm{H}_{2} \mathrm{O}(1: 1) .{ }^{20}$ The disappearance of the starting materials and the quantitative formation of the triazole products were

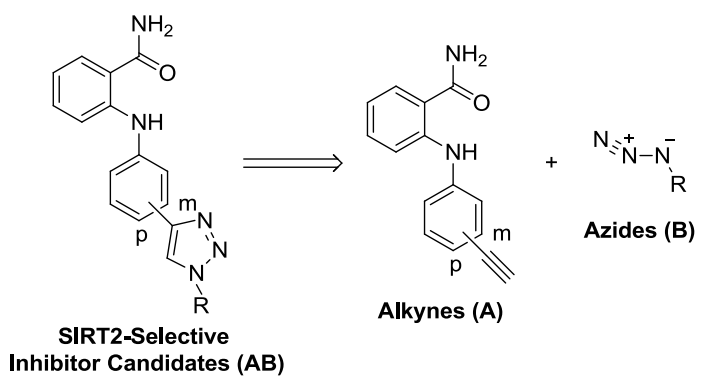

Figure 3. Design of triazole-containing SIRT2-selective inhibitors.

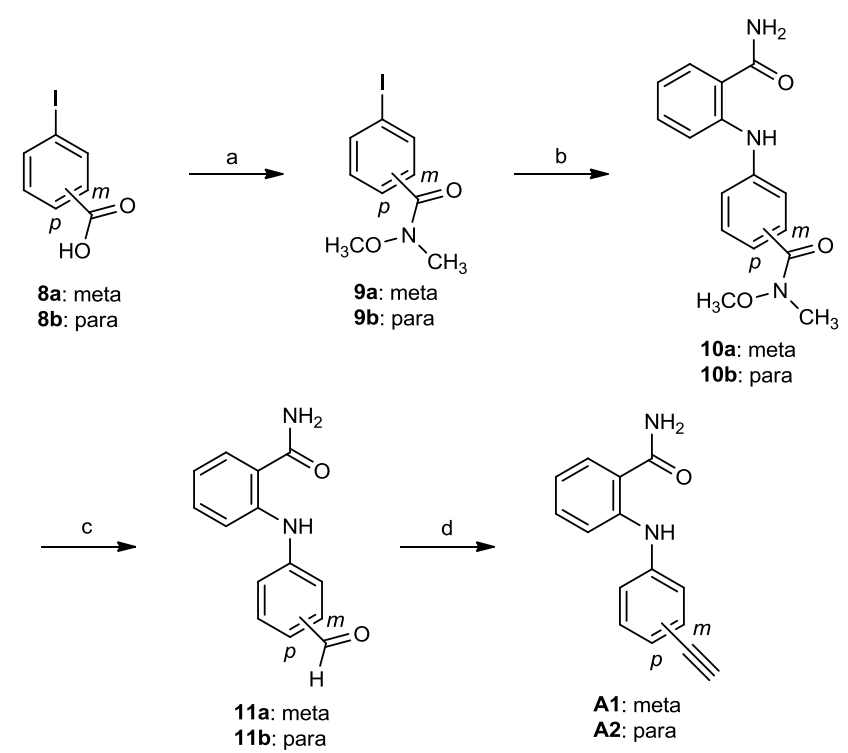

Scheme 1. (a) i) $\mathrm{SOCl}_{2}, \mathrm{CH}_{2} \mathrm{Cl}_{2}$, reflux, ii) $\mathrm{N}, \mathrm{O}$-dimethylhydroxylamine hydrochloride, $\mathrm{Et}_{3} \mathrm{~N}, \mathrm{CH}_{2} \mathrm{Cl}_{2}, \mathrm{rt}, 91 \%$ for $9 \mathbf{a}, 83 \%$ for $\mathbf{9 b}$; (b) 2aminobenzamide, $\mathrm{Pd}_{2} \mathrm{dba}_{3}$, 2-dicyclohexylphosphino-2',4',6'-triisopropyl biphenyl, $\mathrm{K}_{2} \mathrm{CO}_{3}$, tert-BuOH, reflux, $15 \%$ for $\mathbf{1 0 a}, 81 \%$ for $\mathbf{1 0 b}$; (c) $\mathrm{LiAlH}_{4}, \mathrm{THF}, 0^{\circ} \mathrm{C}, 45 \%$ for 11a, q. y. for $11 \mathbf{b}$; (d) dimethyl 1diazoacetonylphosphonate, $\mathrm{MeOH}, \mathrm{rt}, 20 \%$ for $\mathbf{A 1}, 22 \%$ for $\mathbf{A 2}$.

confirmed by TLC and LC-MS (HPLC purity of the resulting triazole and remaining azide: $>95 \%$ ).

These 114 triazole compounds could be screened for SIRT inhibitory activity without further purification. To find SIRT2-selective inhibitors, compounds A1B1-A2B57 were initially tested for activity against SIRT2 at $10 \mu \mathrm{M}^{21}$ In this SIRT2 assay, alkynes (10 $\mu \mathrm{M})$ and azides $(10 \mu \mathrm{M})$ used for this study and a mixture of $\mathrm{CuSO}_{4}(2 \mu \mathrm{M})$, sodium ascorbate $(10 \mu \mathrm{M})$ and TBTA $(2 \mu \mathrm{M})$ were totally inactive. As shown in Fig. 5, two hits emerged from the screen. Crude compounds A1B11 and A2B57 showed SIRT2inhibitory activity comparable to AGK2 (1). Furthermore, at the concentration of $10 \mu \mathrm{M}$, crude A1B11 and A2B57 were totally inactive against SIRT1 and SIRT3 (data not shown), suggesting the SIRT2 selectivity of A1B11 and A2B57. 

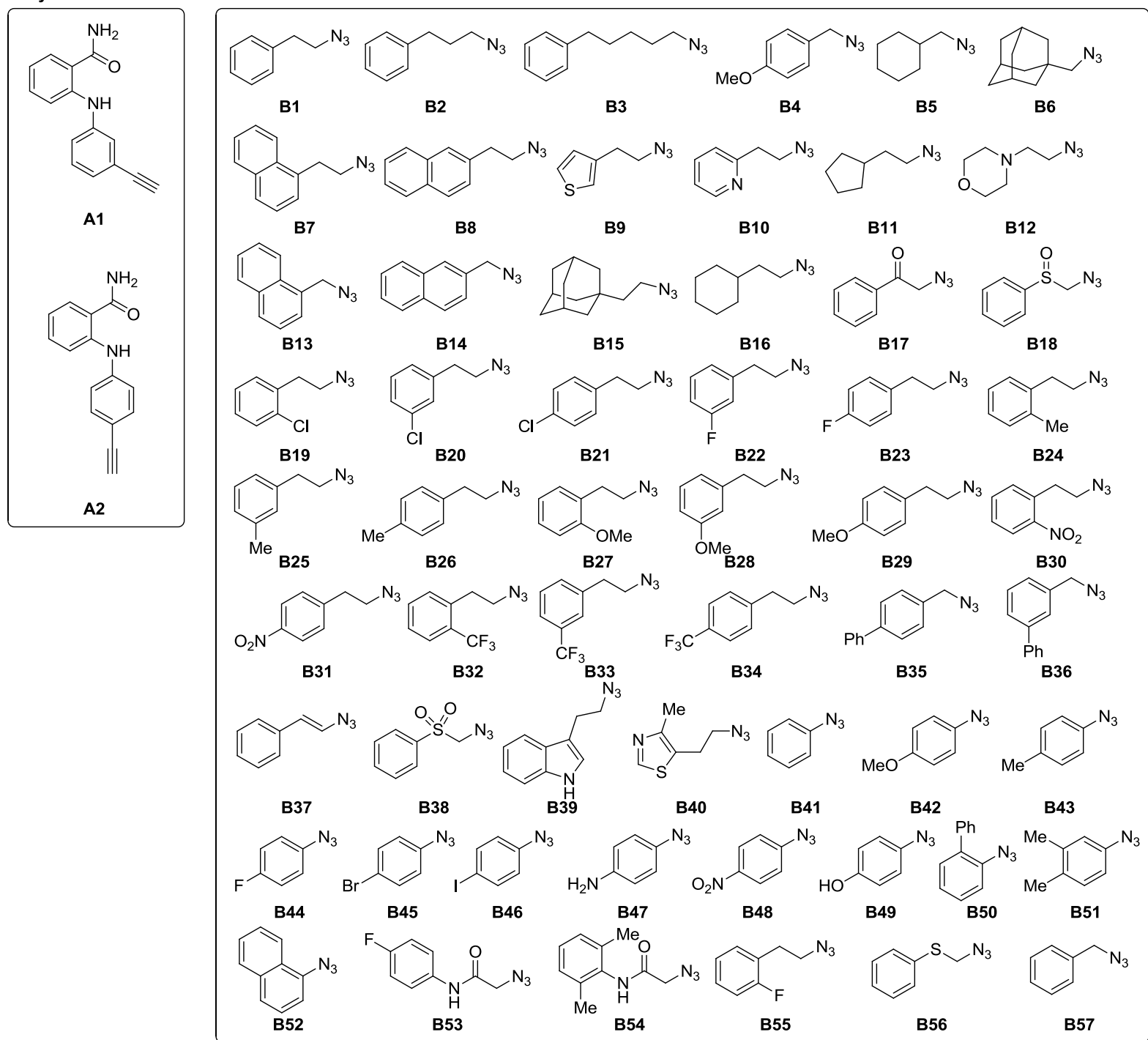

Figure 4. Structures of alkynes $\mathbf{A}$ and azides $\mathbf{B}$ used for this study.

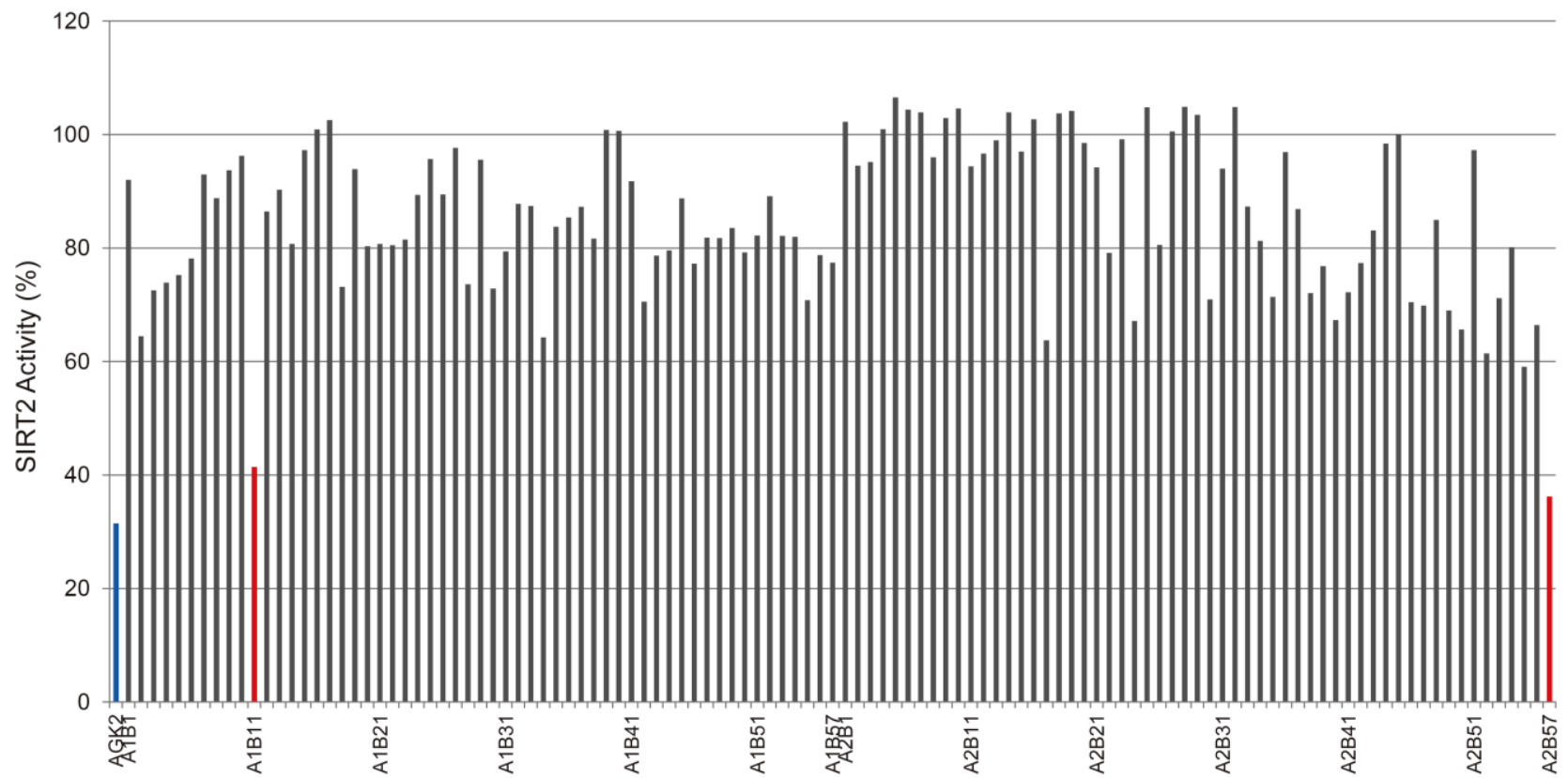

Figure 5. Activity of SIRT2 in the presence of 1142 -anilinobenzamides $(10 \mu \mathrm{M})$. 


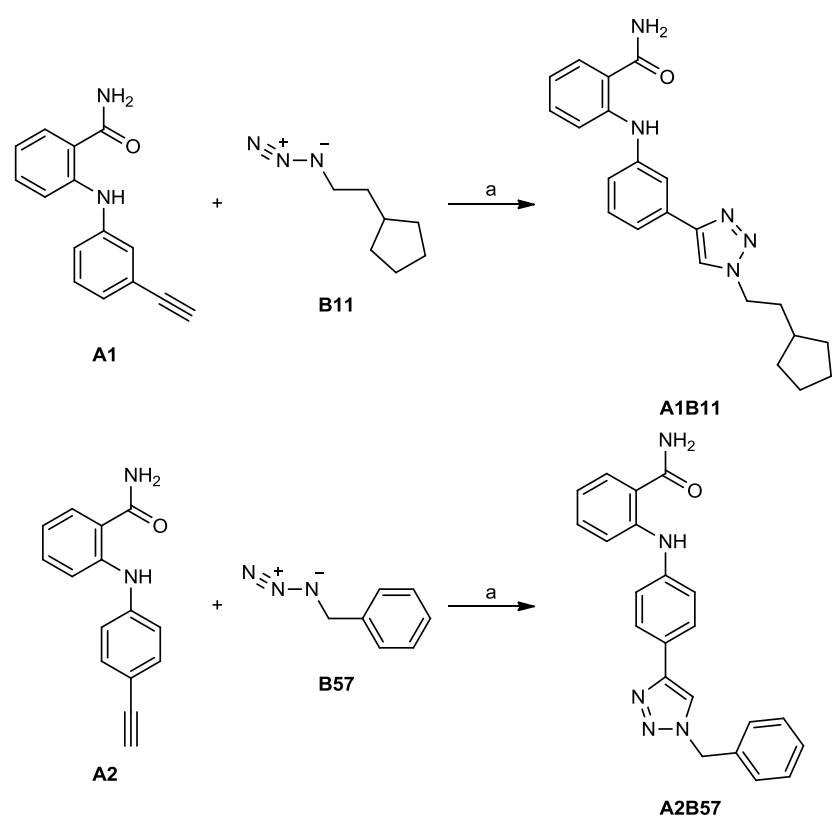

Scheme 2. (a) i) $\mathrm{CuSO}_{4} \cdot 5 \mathrm{H}_{2} \mathrm{O}$, sodium ascorbate, TBTA, DMSO, rt; ii) column chromatography; iii) recrystallization, $20 \%$ for A1B11, 60\% for A2B57.

Because A1B11 and A2B57 used in the primary screening were crude compounds, compounds A1B11 and A2B57 were resynthesized and purified. Scheme 2 illustrates the resynthesis of triazoles A1B11 and A2B57. $\mathrm{Cu}(\mathrm{I})$-catalyzed coupling of alkyne $\mathbf{A 1}$ with B11 and A2 with B57 afforded tirazoles A1B11 and A2B57, respectively. The resynthesized compounds A1B11 and A2B57 were purified by column chromatography and recrystallization. ${ }^{22}$

The pure A1B11 and A2B57 were then examined for inhibitory effects on SIRT2, SIRT1 and SIRT3 ${ }^{21}$ The results of the enzyme assays are shown in Table 1 . In these assays, compounds A1B11 and A2B57 showed potent SIRT2-inhibitory activity with $\mathrm{IC}_{50} \mathrm{~S}$ of $5.3 \mu \mathrm{M}$ and $6.3 \mu \mathrm{M}$, respectively. The SIRT2-inhibitory activity of A1B11 and A2B57 was comparable to that of AGK2 (1). Furthermore, while AGK2 (1) inhibited SIRT1 and SIRT3 with $\mathrm{IC}_{50} \mathrm{~s}$ of $30 \mu \mathrm{M}$ and $91 \mu \mathrm{M}$, respectively, A1B11 and A2B57 did not inhibit either SIRT1 or SIRT3 at concentrations up to $100 \mu \mathrm{M}$, showing high selectivity for SIRT2 over both SIRT1 and SIRT3. Thus, A1B11 and A2B57 are more selective SIRT2 inhibitors than AGK2 (1) in these enzyme assays.

In summary, we have rapidly identified novel SIRT2selective inhibitors by using click chemistry to generate libraries of candidate molecules. The advantage of this work over others is the rapidness of identifying novel SIRT2 inhibitors. It should be possible to obtain even more potent and selective SIRT2 inhibitors by means of further structural development. SIRT2-selective inhibitors are thought to have considerable potential both for the development of novel therapeutic agents and as tools for biological research. Detailed studies of the SIRT2-selective inhibitors and their analogues are under way.

Table 1. SIRT1-, SIRT2 and SIRT3-inhibitory activities of AGK2 (1), A1B11 and A2B57 ${ }^{a}$

\begin{tabular}{cccc}
\hline & \multicolumn{3}{c}{$\mathrm{IC}_{50}(\mu \mathrm{M})$} \\
\cline { 2 - 4 } compound & SIRT2 & SIRT1 & SIRT3 \\
\hline AGK2 & 3.5 & 30 & 91 \\
A1B11 & 5.3 & $>100$ & $>100$ \\
A2B57 & 6.3 & $>100$ & $>100$ \\
${ }^{a}$ Values are the means of at least two experiments.
\end{tabular}

\section{Acknowledgements}

This work was supported in part by a Grant-in-Aid for Scientific Research from the Japan Society for the Promotion of Science (T.S.), JST A-STEP Program (T.S.) and Astellas Foundation for Research on Metabolic Disorders (T.S.), the Tokyo Biochemical Research Foundation (T.S.), and the Uehara Memorial Foundation (T.S.).

\section{References and Notes}

1. Baur, J. A.; Ungvari, Z.; Minor, R. K.; Le Couteur, D. G.; de Cabo, R. Nat. Rev. Drug Discov. 2012, 11, 443.

2. Houtkooper, R. H.; Pirinen, E.; Auwerx, J. Nat. Rev. Mol. Cell. Biol. 2012, 13, 225.

3. Oberdoerffer, P.; Sinclair, D. A. Nat. Rev. Mol. Cell. Biol. 2007, 8, 692.

4. Itoh, Y.; Suzuki, T.; Miyata, N. Curr. Pharm. Des. 2008, 14,529 .

5. North, B. J.; Marshall, B. L.; Borra, M. T.; Denu, J. M.; Verdin, E. Mol. Cell 2003, 11, 437.

6. Jiang, W.; Wang, S.; Xiao, M.; Lin, Y.; Zhou, L.; Lei, Q.; Xiong, Y.; Guan, K. L.; Zhao, S. Mol. Cell 2011, 43, 33.

7. Outeiro, T. F.; Kontopoulos, E.; Altmann, S. M.; Kufareva, I.; Strathearn, K. E.; Amore, A. M.; Volk, C. B.; Maxwell, M. M.; Rochet, J. C.; McLean, P. J.; Young, B.; Abagyan, R.; Feany, M. B.; Hyman, B. T.; Kazantsev, A. G. Science 2007, 317, 516.

8. Taylor, D. M.; Balabadra, U.; Xiang, Z.; Woodman, B.; Meade, S.; Amore, A.; Maxwell, M. M.; Reeves, S.; Bates, G. P.; Luthi-Carter, R.; Lowden, P. A.; Kazantsev, A. G. ACS Chem. Biol. 2011, 6, 540.

9. Trapp, J.; Jochum, A.; Meier, R.; Saunders, L.; Marshall, B.; Kunick, C.; Verdin, E.; Goekjian, P.; Sippl, W.; Jung, M. J. Med. Chem. 2006, 49, 7307.

10. Hoffmann, G.; Breitenbuecher, F.; Schuler, M.; Ehrenhofer-Murray, A. E. J. Biol. Chem. 2014, 289, in press (doi:10.1074/jbc.M113.487736).

11. Medda, F.; Russell, R. J.; Higgins, M.; McCarthy, A. R.; Campbell, J.; Slawin, A. M.; Lane, D. P.; Lain, S.; Westwood, N. J. J. Med. Chem. 2009, 52, 2673. 
12. Suzuki, T.; Imai, K.; Imai, E.; Iida, S.; Ueda, R.; Tsumoto, H.; Nakagawa, H.; Miyata, N. Bioorg. Med. Chem. 2009, 17, 5900.

13. Suzuki, T.; Imai, K.; Nakagawa, H.; Miyata, N. ChemMedChem 2006, 1, 1059.

14. Suzuki, T.; Khan, M. N. A.; Sawada, H.; Imai, E.; Itoh, Y.; Yamatsuta, K.; Tokuda, N.; Takeuchi, J.; Seko, T.; Nakagawa, H.; Miyata, N. J. Med. Chem. 2012, 55, 5760.

15. Srinivasan, R.; Li, J.; Ng, S. L.; Kalesh, K. A.; Yao, S. Q. Nat. Protoc. 2007, 2, 2655.

16. Suzuki, T.; Ota, Y.; Ri, M.; Bando, M.; Gotoh, A.; Itoh, Y.; Tsumoto, H.; Tatum, P. R.; Mizukami, T.; Nakagawa, H.; Iida, S.; Ueda, R.; Shirahige, K.; Miyata, N. J. Med. Chem. 2012, 55, 9562.

17. Suzuki, T.; Kasuya, Y.; Itoh, Y.; Ota, Y.; Zhan, P.; Asamitsu, K.; Nakagawa, H.; Okamoto, T.; Miyata, N. PLoS ONE 2013, 8, e68669.

18. Kolb, H. C.; Finn, M. G.; Sharpless, K. B. Angew. Chem., Int. Ed. 2001, 40, 2004.

19. Suzuki, T.; Ota, Y.; Kasuya, Y.; Mutsuga, M.; Kawamura, Y.; Tsumoto, H.; Nakagawa, H.; Finn, M. G.; Miyata, N. Angew. Chem. Int. Ed. 2010, 49, 6817.

20. The triazole library was prepared using the following procedure: To a solution of alkyne $(25 \mathrm{mM}, 20 \mu \mathrm{L})$, azide (30 mM, $20 \mu \mathrm{L})$, and TBTA $(10 \mathrm{mM}, 10 \mu \mathrm{L})$ in DMSO was added an aqueous solution of $\mathrm{CuSO}_{4} \cdot 5 \mathrm{H}_{2} \mathrm{O}(4 \mathrm{mM}, 25$ $\mu \mathrm{L})$ on a 96-well plate. To the resulting mixture was added an aqueous solution of sodium ascorbate $(20 \mathrm{mM}, 25 \mu \mathrm{L})$, and the mixture was shaken for $24 \mathrm{~h}$ at room temperature. Reactions were monitored by TLC and LCMS. After the reactions were completed, the triazoles were diluted to desired concentrations for enzyme assays by adding DMSO.

21. SIRT activity assay was performed using SIRT fluorimetric drug discovery kits (AK-555, AK-556, and AK-557, BIOMOL Research Laboratories), according to the supplier's protocol. SIRT (human, recombinant) (15 $\mu \mathrm{L} /$ well), $\mathrm{NAD}^{+}(1 \mathrm{mM})$, and various concentrations of samples were incubated at $37^{\circ} \mathrm{C}$ for $60 \mathrm{~min}$, and Fluor de Lys-SIRT substrate $(25 \mu \mathrm{M})$ was added to the mixture. Reactions were stopped after $60 \mathrm{~min}$ by adding Fluor de Lys Developer II with nicotinamide, which stops further deacetylation. Then, $45 \mathrm{~min}$ after addition of this developer, the fluorescence of the wells was measured on a fluorometric reader with excitation set at $360 \mathrm{~nm}$ and emission detection set at $460 \mathrm{~nm}$. The value of $\%$ inhibition was calculated from the fluorescence readings of inhibited wells relative to those of control wells. The compound concentration resulting in $50 \%$ inhibition was determined by plotting $\log$ [Inh] versus the logit function of $\%$ inhibition. $\mathrm{IC}_{50}$ values were determined by means of regression analysis of the concentration/inhibition data.

22. A1B11; mp 56-61 ${ }^{\circ} \mathrm{C} .{ }^{1} \mathrm{H} \mathrm{NMR}\left(\mathrm{CDCl}_{3}, 500 \mathrm{MHz}, \delta\right.$; ppm) $9.58(1 \mathrm{H}, \mathrm{s}), 7.73(1 \mathrm{H}, \mathrm{s}), 7.70(1 \mathrm{H}, \mathrm{s}), 7.52-7.47$ (2H, m), 7.41-7.30 (4H, m), 7.29-7.20 (1H, m), $7.19(1 \mathrm{H}$, $\mathrm{d}, J=8.1 \mathrm{~Hz}), 6.78(1 \mathrm{H}, \mathrm{t}, J=7.0 \mathrm{~Hz}), 4.41(2 \mathrm{H}, \mathrm{t}, J=7.5$ $\mathrm{Hz}), 2.00-1.94(2 \mathrm{H}, \mathrm{m}), 1.81-1.77(4 \mathrm{H}, \mathrm{m}), 1.75-1.60(2 \mathrm{H}$, m), 1.69-1.20 (3H, m). MS (EI) m/z $389\left(\mathrm{M}^{+}\right)$. HRMS (EI) calcd for $\mathrm{C}_{22} \mathrm{H}_{19} \mathrm{~N}_{5} \mathrm{O}$, 389.2216; found, 389.2216. Purity (HPLC) $98 \%$.

A2B57; mp 172-176 ${ }^{\circ} \mathrm{C} .{ }^{1} \mathrm{H}$ NMR $\left(\mathrm{CDCl}_{3}, 500 \mathrm{MHz}, \delta\right.$; ppm) $9.60(1 \mathrm{H}, \mathrm{s}), 7.74(2 \mathrm{H}, \mathrm{d}, J=8.5 \mathrm{~Hz}), 7.61(1 \mathrm{H}, \mathrm{s})$, $7.48(1 \mathrm{H}, \mathrm{d}, J=8.0 \mathrm{~Hz}), 7.42-7.36(4 \mathrm{H}, \mathrm{m}), 7.33-7.29(3 \mathrm{H}$, m), 7.26-7.23 (2H, m), $6.78(1 \mathrm{H}, \mathrm{t}, J=8.0 \mathrm{~Hz}), 5.58$ $(2 \mathrm{H}, \mathrm{s})$. MS (EI) $\mathrm{m} / \mathrm{z} 369\left(\mathrm{M}^{+}\right)$. HRMS (EI) calcd for $\mathrm{C}_{22} \mathrm{H}_{19} \mathrm{~N}_{5} \mathrm{O}$, 369.1590; found, 369.1591. Purity (HPLC) $97 \%$. 
Graphical Abstract

\section{Identification of novel SIRT2-selective inhibitors using a click chemistry approach}

Prima R. Tatum, ${ }^{\mathrm{a}}$ Hideyuki Sawada, ${ }^{\mathrm{b}}$ Yosuke Ota, ${ }^{\mathrm{b}}$ Yukihiro Itoh, ${ }^{\mathrm{b}}$ Peng Zhan, ${ }^{\mathrm{b}}$ Naoya Ieda, ${ }^{\mathrm{a}}$ Hidehiko Nakagawa ${ }^{\mathrm{a}}$ and Naoki Miyata ${ }^{\mathrm{a}, *}$ and Takayoshi Suzuki, ${ }^{\mathrm{b}, *}$

${ }^{a}$ Graduate School of Pharmaceutical Sciences, Nagoya City University, 3-1 Tanabe-dori, Mizuho-ku, Nagoya, Aichi 4678603, Japan

${ }^{\mathrm{b}}$ Graduate School of Medical Science, Kyoto Prefectural University of Medicine, 13 Taishogun Nishitakatsukasa-Cho, Kita-ku, Kyoto 603-8334, Japan

To find novel SIRT2-selective inhibitors, we designed and prepared a library of SIRT inhibitor candidates derived from CuAAC reaction between propargyl 2-anilinobenzamides A and a series of azides B. Screening identified SIRT2selective inhibitors A1B11 and A2B57, which were more SIRT2-selective than AGK2 (1), a known SIRT2 inhibitor. These findings will be useful in the further development of SIRT2-selective inhibitors.
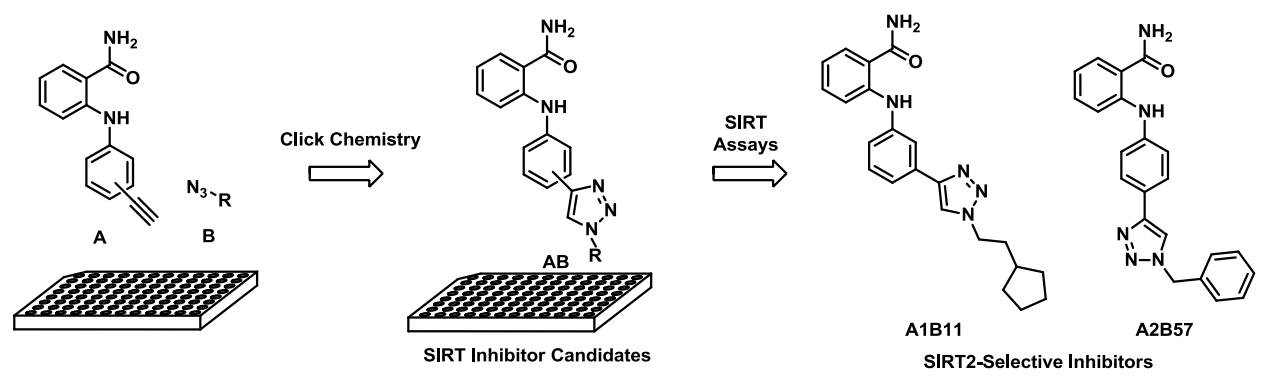